\title{
Variation in male and female mating behaviour among different populations of the two-spot ladybird, Adalia bipunctata (Coleoptera: Coccinellidae)
}

\author{
Penelope R. HADDRILL ${ }^{1 *}$, Michael E.N. MAJERUS ${ }^{1 * *}$ and David M. SHUKER ${ }^{2}$ \\ ${ }^{1}$ Department of Genetics, University of Cambridge, Downing Street, Cambridge CB2 3EH, UK \\ ${ }^{2}$ School of Biology, University of St Andrews, Harold Mitchell Building, St Andrews, Fife KY16 9TH, UK; \\ e-mail: david.shuker@st-andrews.ac.uk
}

Key words. Coccinellidae, Adalia, mating behaviour, sexual selection, two-spot ladybird, UK population, Russian population

\begin{abstract}
Investigating the function of both male and female mating behaviours is essential in our attempts to understand the evolution of mating systems. Variation in mating behaviours among different populations within a species provides a useful opportunity to explore how behaviours may co-vary, although comparative studies are still rather few in number. Population variation in mating behaviour may also have important implications in terms of the evolution of reproductive isolation, the distribution of genetic diversity within and between populations, and the associated ability of those populations to adapt. Here we consider male and female mating behaviour in two populations of the two-spot ladybird, Adalia bipunctata, from the UK and Russia. We find that male and female mating behaviours differ between the populations in terms of the length of female rejection behaviour and the duration of mating, and that this variation is independent of which population an individual's mating partner is from. Our data confirm that patterns of sexual selection and reproductive behaviour are likely to vary across populations in the two-spot ladybird. The extent to which this variation is due to current ecological factors or population history remains to be verified for this species, as for many others.
\end{abstract}

\section{INTRODUCTION}

Understanding both male and female mating behaviours, and the roles they play in determining mating outcomes, is essential if we are to determine the relative importance of the two sexes in the evolution of mating systems, and the extent to which these systems are dominated by sexual conflict and sexually antagonistic evolution (Arnqvist \& Rowe, 2005). This is also of particular importance in our attempts to understand why females mate with specific males, and why they frequently mate more often than appears to be optimal, despite receiving no clear, direct material benefits (Bateman, 1948; Trivers, 1972; Andersson, 1994; Arnqvist \& Nilsson, 2000).

Although variation in reproductive behaviour or morphology within populations and between species has been widely documented, there may also be variation between populations, within a species (e.g. Saarikettu et al., 2005; Shuker et al., 2006; Evans et al., 2011). If populations differ in, for example, sex ratio, density, resource availability, the presence of predators, or any number of other ecological variables, there may be substantial differences in the strength of sexual selection and in the optimal mating rate for either or both of the two sexes (e.g. Kokko \& Rankin, 2006). Studies documenting such variation are less common than single-population studies, limiting our view of, for example, how mating behaviour varies across a species range. Importantly, if populations diverge in terms of their mating behaviour, this may eventually lead to reproductive isolation between them if the differences in behaviour mean that individuals from different populations are less likely to mate with each other than individuals from the same population (Coyne \& Orr, 2004). Conversely, if populations are isolated for extended periods then mating behaviours may evolve to prevent the deleterious effects of inbreeding within them (Charlesworth \& Charlesworth, 1999), or outbreeding between them (Pemberton et al., 1999). Whatever the forces determining their evolution, differences in mating behaviours between populations are likely to lead to differences in the variance in reproductive success between the sexes, and between populations. This has important implications for both the strength and direction of sexual selection, and the relative effective population sizes of the sexes and the different populations. This will in turn influence the distribution of genetic diversity within and between populations and the associated ability of those populations to adapt (Nunney, 1993; Caballero, 1995; Charlesworth, 2001).

Here we consider male and female mating behaviour in two populations of the two-spot ladybird, Adalia bipunctata (Linnaeus). The two-spot ladybird is a naturally promiscuous beetle, with both males and females mating with many different partners throughout their lives both in the laboratory and in the wild (Majerus, 1994; Haddrill et al., 2008). Two-spot ladybird populations are known to

* Present and corresponding address: Institute of Evolutionary Biology, University of Edinburgh, Ashworth Laboratories, King's Buildings, Edinburgh EH9 3JT, UK; e-mail: p.haddrill@ed.ac.uk

** This author is deceased. 
differ in terms of a number of important ecological variables, including the prevalence of different male-killing endosymbiotic bacteria that distort sex-ratios (Majerus \& Hurst, 1997; Hurst et al., 1999; Majerus et al., 2000; Weinert et al., 2007), the infection level of the sexually transmitted mite, Coccipolipus hippodamiae (Webberley et al., 2004), and in the number of generations that are produced each year, with populations from colder climates producing only one generation per year, increasing up to three generations in populations with longer breeding seasons (Majerus, 1994). There is also evidence for genetic differentiation between European populations (Haddrill, 2001), and for other genetic differences, such as variation in the dominance relationships between alleles in the supergene controlling elytral colour and pattern variation; whilst melanic forms are dominant in European and Asian populations, phenotypically similar forms are recessive in populations from North America and New Zealand (Majerus, 1998).

These ecological and genetic differences between twospot ladybird populations may therefore be associated with differences in mating behaviour in one or both of the sexes. Certainly there is evidence for variation in patterns of sexual selection through female mate choice (Majerus et al., 1982a, b; O’Donald \& Majerus, 1992, but see Kearns et al., 1992; Ritchie, 1992; Tomlinson et al., 1995), and although females from different European populations do not differ in the average number of males fathering their offspring, there are suggestions that there is higher variance in the number of fathers in some populations compared to others (Haddrill et al., 2008). This would result in higher variance in male reproductive success in some populations.

We therefore examine both male and female mating behaviour in two populations of two-spot ladybirds, one from the UK and one from Russia. We consider various characteristics of the female rejection response that is almost always observed when a male two-spot ladybird attempts to initiate mating. The rejection response involves a variety of behaviours, including lifting the abdomen at a steep angle to the substrate, kicking back at the male genitalia, running around moving the abdomen from side to side, and rolling over (Majerus, 1994). Females can also pull their abdomen upwards inside the elytra, so the male genitalia physically cannot reach those of the female, and this behaviour completely excludes the possibility of mating occurring. Females may also continue to exhibit rejection behaviour during mating, after the male genitalia have engaged, and this is sometimes associated with a male dismounting before spermatophore formation is complete (Majerus, 1994; Ransford, 1997). Rejection behaviour may function as a mean of preventing mating from occurring, or as a means of testing males, or both (Majerus, 1994; Perry et al., 2009, Haddrill et al., unpubl. data). If females in different populations are more or less willing to mate, or if they prefer to mate with males from their own or different populations, they may therefore adjust the level of rejection behaviour when they encounter different males.
In addition, males may adjust their own mating behaviour in response to females from different populations. Mating bouts in two-spot ladybirds can consist of between one and three insemination episodes, each termed a "cycle". Each cycle represents the formation of a new spermatophore within the female's reproductive tract, and the male genitalia are not disengaged between cycles. For every additional cycle of mating, males therefore transfer greater numbers of sperm to the female (Ransford, 1997), and longer copulations have been shown to result in increased levels of paternity achieved by a male (Haddrill et al., 2008). Males may therefore adjust the number of cycles of mating they carry out with different females, and there is evidence of strategic ejaculate investment in this species (Perry \& Rowe, 2010).

We therefore assess whether either of the sexes adjust their mating behaviour in response to individuals from their own or different populations. We find that both female and male mating behaviours differ between the two populations, but that this variation is independent of the population of origin of an individual's partner.

\section{MATERIAL AND METHODS}

Experimental individuals were taken from laboratory stocks that originated in Cambridge, UK and from the Ural Mountain region of Russia. Both population stocks had been maintained under identical laboratory conditions for several years with reproducing individuals housed in equal sex-ratio groups of ten beetles and fed pea aphids (Acyrthosiphon pisum), and nonreproducing individuals maintained at $4{ }^{\circ} \mathrm{C}$ and fed a diet of artificial food (see Majerus \& Kearns, 1989 for details) to mimic overwintering conditions. Populations originating from the UK and Russia are known to differ in a number of ecological variables. For example, whilst Russian populations are known to be infected with the mite, Coccipolipus hippodamiae, this species has never been found infecting UK populations of two-spots (Webberley et al., 2006). Populations from the UK and Russia also differ in terms of infection with male-killing bacterial endosymbionts. Both Rickettsia and Spiroplasma infections have been identified in UK populations (Weinert et al., 2007), although the Cambridge population has only been found to be infected with the Rickettsia bacteria, at a prevalence of around 7\% (Hurst et al., 1993). Russian populations also harbour both Rickettsia and Spiroplasma infections, with prevalence estimates ranging from $5-50 \%$ and $18-44 \%$, respectively (Schulenburg et al., 2002; Shaikevich et al., 2012). However, some Russian populations have also been identified as being infected with the bacteria Wolbachia, with prevalence estimates of around 23\% (Schulenburg et al., 2002). These differences, and the associated differences in female fecundity and sex ratio may have important implications for patterns of mating behaviour in these populations.

Ten newly-eclosed virgin pairs of brothers and ten virgin pairs of sisters were selected from each population, housed individually and fed pea aphids (Acyrthosiphon pisum) ad libitum for seven days to ensure reproductive maturity. Pronotum width was measured for all individuals using digital calipers and there was no difference in size between groups of males or groups of females from the two populations $(P>0.05)$. Only individuals of the "typica" phenotype were used. These individuals, in sibling pairs, were then randomly assigned to one of ten repeats of each of the following mating trials:

(1) UK female $\times$ UK male ("same population" mating) 
TABLE 1. Mating and rejection behaviour measures for mating trials between females and males originating from the UK and Russia.

\begin{tabular}{lcccc}
\hline & UK female $\times$ & UK female $\times$ & Russian female $\times$ & \multicolumn{2}{c}{ Russian female $\times$} \\
UK male \\
\hline No. of females mating (\%) & UK male & Russian male & Russian male & $8(89)$ \\
No. of females exhibiting any rejection behaviour (\%) & $7(78)$ & $9(100)$ & $7(78)$ & $7(78)$ \\
No. of females exhibiting abdomen pulling (\%) & $1(11)$ & $1(56)$ & $9(100)$ & $3(33)$ \\
Total length of rejection behaviour [seconds (SE)] & $108.88(44.97)$ & $67.33(32.08)$ & $199.71(73.23)$ & $101.88(40.94)$ \\
Rejection behaviour before mating began [seconds (SE)] & $10.11(7.44)$ & $4.89(4.89)$ & $164.33(60.90)$ & $49.55(26.15)$ \\
Rejection time after mating began [seconds (SE)] & $105.63(44.92)$ & $62.44(32.23)$ & $44.86(25.88)$ & $50.38(29.53)$ \\
No. of cycles of mating & $2.25(0.25)$ & $2.56(0.24)$ & $2.71(0.18)$ & $2.00(0.19)$ \\
Time spent in copula [minutes (SE)] & $220.11(31.05)$ & $282.77(36.71)$ & $241.06(15.12)$ & $203.03(25.73)$ \\
\hline
\end{tabular}

Sample size $=9$ in all cases

(2) UK female $\times$ Russian male ("different population" mating)

(3) Russian female $\times$ Russian male ("same population" mating)

(4) Russian female $\times$ UK male (“different population" mating)

Each female was transferred to a clean $9 \mathrm{~cm}$ petri dish on a mating platform with their allocated male. Pairs were observed for $30 \mathrm{~min}$ and the length of any rejection and/or mating behaviour recorded. Rejection behaviour was recorded both before mating began, and during mating (after engagement of genitalia), where appropriate. We also recorded whether females exhibited the specific behaviour of pulling the abdomen upwards inside the elytra. When mating did occur, we recorded the length of mating, both in terms of the duration in minutes and the number of cycles of mating (i.e. the number of insemination bouts within a single mount; see above). As a single cycle of mating progresses, the positioning of the male on the female changes, such that the beginning of a new cycle can reliably be identified (Majerus, 1994). In four trials (one of each of the four mating trial categories listed above), no mating attempt was made (i.e. the male made no attempt to mount the female), so these trials were excluded from the analysis. Of the 36 mating trials during which a mating attempt was made, there were four instances where mating did not occur (two Russian female $\times$ Russian male, one UK female $\times$ UK male and one Russian female $\times$ UK male). However, the rejection behaviour that had occurred between these pairs was still included in the data for rejection behaviour before mating began and counts of the number of females exhibiting the abdomen pulling behaviour. In all of these cases the male mating attempt was successfully rejected within five minutes, and no further mating attempts were made during the remainder of the $30 \mathrm{~min}$ observation period, so the pairs were separated.

\section{RESULTS}

We first investigated whether the specific population of origin of experimental individuals of either sex had any effect on mating behaviour. Measures of mating and rejection behaviour for individuals from the UK and Russian populations are shown in Tables 1 and 2. Although female population of origin did not influence the number of females who ultimately mated (G-test of heterogeneity; $\left.G_{1}=1.17, P=0.28\right)$, it did have significant effects on rejection behaviour, with Russian females more likely to exhibit the abdomen pulling behaviour (G-test of heterogeneity; $G_{1}=6.81, P=0.009$ ) and performing rejection behaviour for significantly longer prior to the commencement of mating (Mann-Whitney U-test; rejection time before mating began, $U_{18,18}=80.5, P=0.003$, see Fig. 1). These results were both independent of the population of origin of the male attempting to mate; i.e. Russian

TABLE 2. Mating and rejection behaviour measures for females and males originating from the UK population or the Russian population, and for females presented with males from the same population as their own, or from a different population.

\begin{tabular}{lcccc}
\hline & UK population & Russian population & Same population & Different population \\
\hline $\begin{array}{l}\text { No. of females mating (\%) } \\
\begin{array}{l}\text { No. of females exhibiting } \\
\text { any rejection behaviour (\%) }\end{array}\end{array}$ & $17(94)$ & $15(83)$ & $15(83)$ & $17(94)$ \\
$\begin{array}{l}\text { No. of females exhibiting } \\
\text { abdomen pulling (\%) }\end{array}$ & $2(11)$ & $16(89)$ & $16(89)$ & $12(67)$ \\
$\begin{array}{l}\text { Total length of rejection } \\
\text { behaviour [seconds (SE)] }\end{array}$ & $86.88(26.75)$ & $147.53(41.10)$ & $151.27(41.93)$ & $83.59(25.22)$ \\
$\begin{array}{l}\text { Rejection behaviour before mating } \\
\text { began [seconds (SE)] }\end{array}$ & $7.50(8.73)$ & $106.94(35.03)$ & $87.22(35.15)$ & $27.22(13.99)$ \\
$\begin{array}{l}\text { Rejection time after mating } \\
\text { began [seconds (SE)] }\end{array}$ & $82.76(26.82)$ & $47.80(19.16)$ & $77.27(27.16)$ & $56.77(21.37)$ \\
$\begin{array}{l}\text { No. of cycles of mating } \\
\text { Time spent in copula [minutes (SE)] }\end{array}$ & $211.57(19.60)$ & $264.52(21.75)$ & $229.89(17.63)$ & $245.25(24.33)$ \\
\hline
\end{tabular}

Sample size $=18$ in all cases 


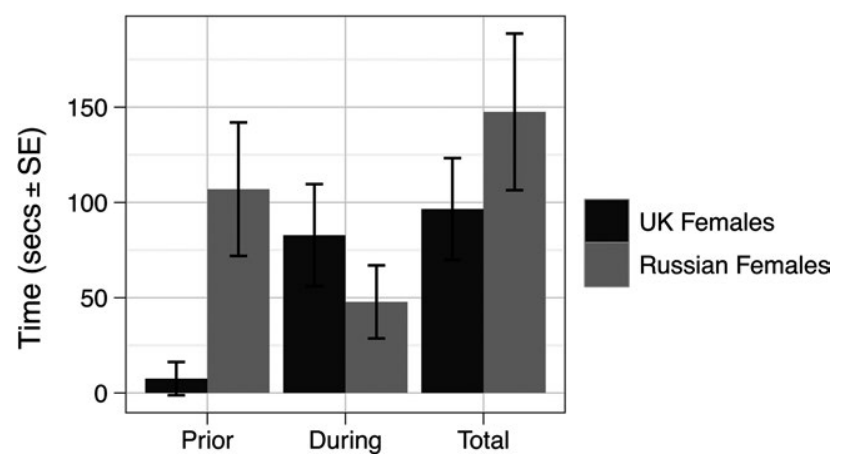

Fig. 1. Length of time in seconds that female two-spot ladybirds originating from a UK population and a Russian population exhibited rejection behaviour in response to a male mating attempt. Rejection behaviour was measured prior to mating beginning, during mating (if appropriate), and in total.

females rejected more often and for longer regardless of whether the male attempting to mate came from their own or the other population (see below). The differences between UK and Russian females in rejection time after mating began (Mann-Whitney U-test; $U_{18,18}=152 P=$ 0.37 ) and total rejection time (Mann-Whitney U-test; $U_{18}$, ${ }_{18}=205 P=0.18$ ) were not significant.

There was also a significant effect of male origin on the length of mating in terms of the number of cycles of mating, i.e. in terms of the number of spermatophores transferred within a single mating. UK males were more likely to carry out two cycles of insemination within a given copulation bout, whilst Russian males were more likely to carry out three (G-test of heterogeneity; $G_{2}=6.39, P=$ 0.041 , see Fig. 2). As above, this was independent of the population of origin of the female; i.e. Russian males mated for longer regardless of whether they were mating with females from their own or the other population (see below) and thus there was no difference in the number of cycles of mating received by females from different populations. This difference in number of cycles of mating between Russian and UK males did not result in a difference in the amount of time spent in copula (although the difference is close to significance; unpaired t-test, $t_{30}=$ $-1.81, P=0.08)$. It therefore appears that both males and females from different populations differ in their mating behaviour, but that this is unaffected by the population of origin of their mating partner.

We therefore went on to test whether male and female mating behaviours were affected by whether an experimental individual's partner in the mating trial came from the same population or a different population to themselves. Table 2 also shows the descriptive statistics for female rejection and mating behaviour in response to males from their own or different populations. There was no difference in the number of females that mated (G-test of heterogeneity; $\left.G_{1}=1.17, P=0.28\right)$, that exhibited any type of rejection behaviour $\left(G_{1}=2.67, P=0.10\right)$, or that exhibited the abdomen pulling behaviour $\left(G_{1}=1.19, P=\right.$ 0.28 ) in terms of the population of origin of the male. In terms of the length of time females spent rejecting males, there was a tendency for females to reject males from

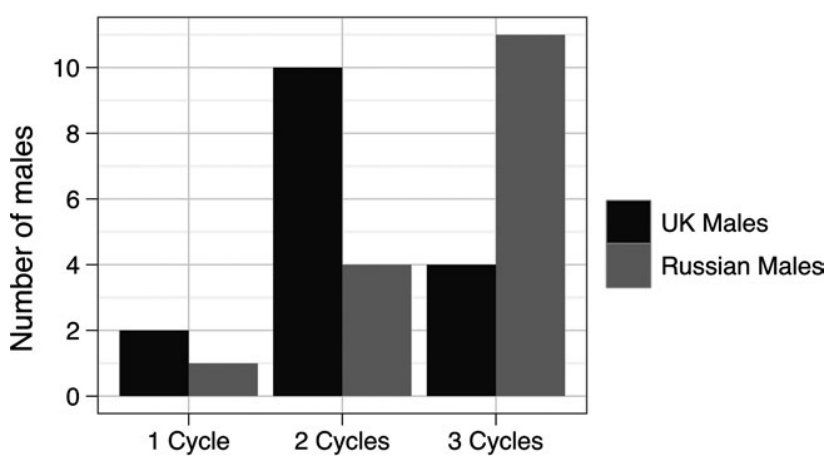

Fig. 2. Number of cycles of mating carried out by male twospot ladybirds originating from a UK population and a Russian population.

their own population for longer, but this effect was not significant for any measure of rejection behaviour (MannWhitney U-test: total rejection time, $U_{18,18}=91, P=0.16$; rejection time before mating began, $U_{18,18}=132, P=$ 0.28 ; rejection time after mating began, $U_{18,18}=107, P=$ 0.43 ). Females therefore do not seem to vary their rejection behaviour in response to males from their own or a different population. There was also no evidence for males adjusting their mating behaviour in response to females from their own or different populations (see Table 2). There was no difference in the length of mating between "same population" and "different population" mating trials, either in terms of the number of cycles of mating (i.e. the number of insemination bouts within a single mating, G-test of heterogeneity; $G_{2}=0.57, P=$ 0.75 ) or the time spent in copula (unpaired t-test: $t_{30}=$ $0.49, P=0.62)$.

\section{DISCUSSION}

We examined the rejection and mating behaviour of both male and female two-spot ladybirds originating from populations in the UK and Russia, in order to test first whether ladybird behaviour varies across populations, and second if such variation depended on whether individuals encounter mating partners from the same population of origin as their own, or from a different population. Components of both the male and female mating behaviour repertoire differed between the two populations, with the most notable being female rejection behaviour and male insemination behaviour. There was also a tendency for females to reject males from their own population for longer, but males did not adjust their mating behaviour in response to females from the same or different populations. Given that the number of copulation or insemination cycles has been shown to be a major determinant of the number of sperm transferred (Ransford, 1997), this suggests that males invest similar numbers of sperm with females from their own and different populations. This finding indicates that the number of insemination cycles is a trait that is primarily associated with the male, rather than a function of both male and female. Unfortunately we were unable to collect data on the ultimate paternity success of males mating with females from different populations, but in future it would be interesting to deter- 
mine whether the similar mating durations observed when males mated with females from their own or different populations translated into similar levels of paternity secured with different females, and conversely whether the difference in mating duration between Russian and UK males translated into different levels of fertilisation success.

We found significant differences in both male and female mating behaviour between the two populations. Females from the Russian population rejected males for significantly longer than females from the UK population, regardless of the population of origin of the male attempting to mate. Russian females were also more likely to exhibit the specific abdomen pulling rejection behaviour, which completely precludes the occurrence of mating because the male genitalia are physically unable to reach those of the female. Russian females thus exhibit stronger rejection responses than their UK counterparts, suggesting that they are either more reluctant to mate, or they are more choosy about who they mate with. Whilst females from the UK population have been shown to be highly polyandrous, producing offspring from between one and six males (Haddrill et al., 2008), it is possible that Russian females mate with fewer males. Given that there is evidence to suggest that around five to six matings are optimal for females from the UK population in terms of the hatchability of their eggs (Haddrill et al., 2007), this suggests that Russian females may mate at rates less than optimal, or that the optimal level of mating also varies between populations.

We also found evidence that males from the two populations differ in their mating behaviour, with UK males more likely to carry out two cycles of mating, whilst Russian males are more likely to carry out three. Given that mating duration has been shown to be a strong determinant of the level of paternity that a male achieves in both the UK and a Dutch population (Ransford, 1994; de Jong et al., 1998; Haddrill et al., 2008), if the same is true of the Russian population then this suggests that Russian males transfer a larger quantity of sperm to females, and therefore sire a larger fraction of a female's offspring. It is interesting to speculate that if Russian females tend to mate at lower rates than UK females, there may be selection pressure on Russian males to mate for longer in order to increase their sperm competitiveness. Conversely, if UK females tend to mate at a higher rate, the best male strategy may be to carry out a larger number of shorter matings. In support of this, de Jong et al. (1998) showed that in a Dutch population of two-spots, both female rejection behaviour and male insemination behaviour were adjusted in response to female mating history, although in contrast to the scenario outlined above, they found that when females had mated at a high frequency they exhibited more rejection behaviour, and subsequent matings were longer than when females had mated only once. However, whilst their study examined the mating behaviour of multiply mated non-virgin individuals, the experimental individuals used here were all virgins and mated only once. It is likely that the mating decisions of both males and females differ depending on their mating history, and so it would be interesting to extend our study in future to examine how both male and female mating behaviours differ across a number of matings with partners from different populations.

Comparing within- and between-population interactions, our results suggest that whilst there does not appear to be an effect of the risk of outbreeding, for example due to the disruption of local adaptations or coadapted groups of genes (Templeton, 1986), there may be some effect of the risk of inbreeding within populations on female mating behaviour, with females tending to reject males from their own population for longer than males from other populations. Two-spot populations are known to suffer very severe inbreeding depression, with inbred stocks only surviving two or three generations in the laboratory before fertility and egg survival declines to the point where most lines fail to produce any progeny (Majerus, 1994). Selection may therefore strongly favour females who avoid mating with related males or with males from the same population as themselves (Hurst et al., 1996). Inbreeding avoidance may also in part explain the high levels of polyandry in two-spots (e.g. Michalczyk et al., 2011). Whilst relatively small sample sizes mean that we cannot draw any definitive conclusions from our data, the effect may be more pronounced if females experience mating attempts from close relatives. Alternatively, females may mate randomly with respect to the relatedness of their mate and bias paternity away from more closely related males, as has been shown in other species (e.g. Tregenza \& Wedell, 2002; Bretman et al., 2004). One additional point of note is that given that matings between individuals from different populations were no less likely than matings between individuals from the same population, this suggests that there is little evidence of reproductive isolation between our two study populations, despite significant geographical isolation between them. It is possible that reproductive isolation may be less easy to evolve in highly promiscuous species, due to continued gene flow in regions of parapatry (Parker \& Partridge, 1998).

These results all suggest that the strength and direction of sexual selection may vary between these two populations. The rate of female multiple mating and the level of male sperm precedence are key parameters in determining the optimal mating strategy for males and females, and to what extent the mating system is evolving under sexual conflict (e.g. Arnqvist \& Rowe, 2005). These differences are also likely to translate into differences in the variance in reproductive success both between the sexes and between populations, and this has important implications for the distribution of genetic diversity within and between populations (Nunney, 1993; Caballero, 1995; Charlesworth, 2001). Variation in sexual selection and mating behaviour between populations will therefore have significant consequences for the ability of species to adapt.

ACKNOWLEDGEMENTS. This work was supported by a BBSRC studentship to PRH and a NERC Advanced Fellowship 
to DMS. PRH is supported by a NERC Postdoctoral Research Fellowship. We thank D. Bertrand, M. Chyb, R. Day, D. Farrington and I. Wright for technical assistance with ladybird work, and two reviewers for comments on the manuscript.

\section{REFERENCES}

Andersson M. 1994: Sexual Selection. Princeton University Press, New Jersey, 624 pp.

Arnqvist G. \& NiLsson T. 2000: The evolution of polyandry: multiple mating and female fitness in insects. - Anim. Behav. 60: 145-164.

Arnqvist G. \& Rowe L. 2005: Sexual Conflict. Princeton University Press, New Jersey, $360 \mathrm{pp}$.

Bateman A.J. 1948: Intra-sexual selection in Drosophila. Heredity 2: 349-368.

Bretman A., Wedell N. \& Tregenza T. 2004: Molecular evidence of post-copulatory inbreeding avoidance in the field cricket Gryllus bimaculatus. - Proc. R. Soc. Lond. (B) 271: 159-164.

Caballero A. 1995: On the effective size of populations with separate sexes, with particular reference to sex-linked genes. - Genetics 139: 1007-1011.

Charlesworth B. 2001: The effect of life-history and mode of inheritance on neutral genetic variability. - Gen. Res. 77: 153-166.

Charlesworth B. \& Charlesworth D. 1999: The genetic basis of inbreeding depression. - Gen. Res. 74: 329-340.

Coyne J.A. \& OrR H.A. 2004: Speciation. Sinauer Associates, Sunderland, MA, $545 \mathrm{pp}$.

de Jong P.W., Brakefield P.M. \& Geerinck B.P. 1998: The effect of female mating history on sperm precedence in the two-spot ladybird, Adalia bipunctata (Coleoptera, Coccinellidae). - Behav. Ecol. 9: 559-565.

Evans J.P., Gasparini C., Holwell G.I., Ramnarine I.W., Pitcher T.E. \& Pilastro A. 2011: Intraspecific evidence from guppies for correlated patterns of male and female genital trait diversification. - Proc. R. Soc. Lond. (B) 278: 2611-2620.

HadDRILl P.R. 2001: The Development and Use of Molecular Genetic Markers to Study Sexual Selection and Population Genetics in the Two-spot Ladybird, Adalia bipunctata (L.). $\mathrm{Ph} . D$. thesis, University of Cambridge, $262 \mathrm{pp}$.

Haddrill P.R., Shuker D.M., Mayes S. \& Majerus M.E.N. 2007: Temporal effects of multiple mating on components of fitness in the two-spot ladybird, Adalia bipunctata (Coleoptera: Coccinellidae). — Eur. J. Entomol. 104: 393-398.

Haddrill P.R., Shuker D.M., Amos W., Majerus M.E.N. \& Mayes S. 2008: Female multiple mating in wild and laboratory populations of the two-spot ladybird, Adalia bipunctata. - Mol. Ecol. 17: 3189-3197.

Hurst G.D.D., Majerus M.E.N. \& Walker L.E. 1993: The importance of cytoplasmic male killing elements in natural populations of the two spot ladybird, Adalia bipunctata (Linnaeus) (Coleoptera: Coccinellidae). — Biol. J. Linn. Soc. 49: 195-202.

Hurst G.D.D., Sloggett J.J. \& Majerus M.E.N. 1996: Estimation of the rate of inbreeding in a natural population of Adalia bipunctata (Coleoptera: Coccinellidae) using a phenotypic indicator. - Eur. J. Entomol. 93: 145-150.

Hurst G.D.D., Schulenburg J.H.G.v.D., Majerus T.M.O., BerTRAND D., ZaKharov I.A., BaUngaARD J., VolKL W., Stouthamer R. \& Majerus M.E.N. 1999: Invasion of one insect species, Adalia bipunctata, by two different malekilling bacteria. - Insect Mol. Biol. 8: 133-139.
Kearns P.W.E., Tomlinson I.P.M., Veltman C.J. \& O’Donald P. 1992: Non-random mating in the two-spot ladybird (Adalia bipunctata): II. Further tests for female mating preference. Heredity 68: 385-389.

Kокко H. \& RANKIN D.J. 2006: Lonely hearts or sex in the city? Density-dependent effects in mating systems. - Phil. Trans. R. Soc. Lond. (B) 361: 319-334.

MaJERus M.E.N. 1994: Ladybirds. Harper Collins, London, 367 pp.

Majerus M.E.N. 1998: Melanism: Evolution in Action. Oxford University Press, Oxford, 364 pp.

Majerus M.E.N. \& Hurst G.D.D. 1997: Ladybirds as a model system for the study of male-killing symbionts. - Entomophaga 42: 13-20.

Majerus M.E.N. \& Kearns P.W.E. 1989: Ladybirds. Richmond Publishing, Slough, 103 pp.

Majerus M.E.N., O'Donald P. \& WeIr J. 1982a: Evidence for preferential mating in Adalia bipunctata. - Heredity 42: $57-65$.

Majerus M.E.N., O'Donald P. \& Weir J. 1982b: Female mating preference is genetic. - Nature 300: 521-523.

Majerus M.E.N., Schulenburg J.H.G.v.D. \& ZaKharov I.A. 2000: Multiple causes of male-killing in a single sample of the two-spot ladybird Adalia bipunctata (Coleoptera: Coccinellidae). - Heredity 84: 605-609.

Michalczyk L., Millard A.L., Martin O.Y., Lumley A.J., Emerson B.C., Chapman T. \& Gage M.J.G. 2011: Inbreeding promotes female promiscuity. - Science 333: 1739.

NunNEY L. 1993: The influence of mating system and overlapping generations on effective population size. - Evolution 47: $1329-1341$.

O’Donald P. \& Majerus M.E.N. 1992: Non-random mating in Adalia bipunctata (the two-spot ladybird). III. New evidence of genetic preference. - Heredity 69: 521-526.

Parker G.A. \& PArtridge L. 1998: Sexual conflict and speciation. - Phil. Trans. R. Soc. Lond. (B) 353: 261-274.

Pemberton J.M., Coltman D.W., Coulson T.N. \& Slate J. 1999: Using microsatellites to measure the fitness consequences of inbreeding and outbreeding. In Goldstein D.B. \& Schlötterer C. (eds): Microsatellites: Evolution and Application, Oxford University Press, Oxford, pp. 151-164.

Perry J.C. \& Rowe L. 2010: Condition-dependent ejaculate size and composition in a ladybird beetle. - Proc. R. Soc. Lond. (B) 277: 3639-3647.

Perry J.C., Sharpe D.M.T. \& Rowe L. 2009: Conditiondependent female re-mating resistance generates sexual selection on male size in a ladybird beetle. - Anim. Behav. 77: 743-748.

RANSFORD M.O. 1997: Sperm Competition in the 2-spot Ladybird, Adalia bipunctata. $\mathrm{PhD}$ thesis, University of Cambridge, $244 \mathrm{pp}$.

Ritchie M.G. 1992: Setbacks in the search for mate-preference genes. - Trends Ecol. Evol. 7: 328-329.

SaArikettu M., Liimatainen J.O. \& Hoikkala A. 2005: Intraspecific variation in mating behaviour does not cause sexual isolation between Drosophila virilis strains. - Anim. Behav. 70: 417-426.

Schulenburg J.H.G.v.D., Hurst G.D.D., Tetzlaff D., Booth G.E., Zakharov I.A. \& Majerus M.E.N. 2002: History of infection with different male-killing bacteria in the two-spot ladybird beetle Adalia bipunctata revealed through mitochondrial DNA sequence analysis. - Genetics 160: 1075-1086.

Shaikevich E.V., Ivshina E.V. \& Zakharov I.A. 2012: Polymorphism of mitochondrial DNA and distribution of cytoplasmic symbionts in the populations of two-spot ladybird beetle Adalia bipunctata. - Russ. J. Genet. 48: 567-571. 
Shuker D.M., Ballantyne G.A. \& Wedell N. 2006: Variation in the cost to females of sexual conflict over mating in the seed bug Lygaeus equestris (Hemiptera: Lygaeidae). - Anim. Behav. 72: 313-321.

Templeton A.R. 1986. Coadaptation and outbreeding depression. In Soulé M.E. (ed.): Conservation Biology - the Science of Scarcity and Diversity. Sinauer Associates, Sunderland, MA, pp. 105-116.

Tomlinson I.P.M., Kearns P.W.E. \& Veltman C.J. 1995: Nonrandom mating in the two-spot ladybird (Adalia bipunctata) The influence of weight on mating success. - Behav. Genet. 25: 467-474.

Tregenza T. \& Wedell N. 2002: Polyandrous females avoid costs of inbreeding. - Nature 415: 71-73.

TRIVERs R.L. 1972: Parental investment and sexual selection. In Campbell B. (ed): Sexual Selection and the Descent of Man. Heineman, London, pp. 136-179.
Webberley K.M., Hurst G.D.D., Husband R.W., Schulenburg J.H.G.v.D., Sloggett J.J., Isham V., Busko J. \& Majerus M.E.N. 2004: Host reproductive and a sexually transmitted disease: causes and consequences of Coccipolipus hippodamiae distribution on coccinellid beetles. - J. Anim. Ecol. 73: $1-10$.

Webberley K.M., Tinsley M.C., Sloggett J.J., Majerus M.E.N. \& HURST G.D.D. 2006: Spatial variation in the incidence of a sexually transmitted parasite of the ladybird beetle Adalia bipunctata (Coleoptera: Coccinellidae). - Eur. J. Entomol. 103: 793-797.

Weinert L.A., Tinsley M.C., Temperley M. \& Jiggins F.M. 2007: Are we underestimating the diversity and incidence of insect bacterial symbionts? A case study in ladybird beetles. —Biol. Lett. 3: 678-681.

Received August 16, 2012; revised and accepted October 8, 2012 